\title{
Gastric ischaemia following a fall
}

\author{
Michael John Dunne, ${ }^{1}$ Irina Ferreira, ${ }^{1}$ Ben Thorpe, ${ }^{2}$ Ala Ajeel, ${ }^{1}$ Haythem Ali, ${ }^{3}$ Charles Bailey ${ }^{1}$ \\ 1'Department of General Surgery, Kent and Sussex Hospital, Tunbridge Wells, UK; \\ 2Department of Anaesthetics, Kent and Sussex Hospital, Tunbridge Wells, UK: \\ ${ }^{3}$ Department of General Surgery, Maidstone Hospital, Maidstone, UK
}

Correspondence to Dr Michael John Dunne, mikedunne@doctors.org.uk

\section{Summary}

A previously well 73-year-old gentleman presented 5 days after a fall from 6 feet from a ladder with abdominal pain and vomiting. X-rays demonstrated evidence of bowel perforation. On arrival, the patient was peritonitic and displayed a severely septic picture. He was subsequently taken for emergency laparotomy. A $5 \mathrm{~mm}$ perforation was found in the small bowel which was repaired but unusually a large segment in the fundus and greater curvature of the stomach was found to be necrotic. A partial gastrectomy was performed and histology confirmed ischaemia likely to be secondary to trauma. The patient has now been successfully discharged home.

\section{BACKGROUND}

Cases of gastric ischaemia are very rare but are important to consider as they are associated with a high mortality following surgical resection of necrotic tissue. A number of cases have been described relating to a number of causes ranging from ingestion of caustic substances to extreme acute gastric dilatation. We present an unusual presentation of concurrent small bowel perforation and gastric necrosis following an incidence of low impact trauma.

\section{CASE PRESENTATION}

A 73-year-old gentleman presented to accident and emergency with a 5-day history of increasing lower abdominal pain and vomiting. He had fallen approximately 6 feet from a ladder on to his left hand side on the grass and he had only some muscular type chest pain at the time of injury. He was seen in the community by a duty doctor who examined him and found nothing remarkable aside from some costal pain around the level of the 5th rib on the left side which was attributed to fracture following trauma. He was, however, bed bound from the time of his injury and on day 3 began vomiting coffee ground vomitus approximately 3-4 times a day. This continued until his condition deteriorated significantly on day 5 and he was blue lighted to our emergency department.

$\mathrm{He}$ had a history of benign prostatic hypertrophy and allergic asthma and was taking tamsulosin $400 \mathrm{mcg}$ and salbutamol as required.

\section{INVESTIGATIONS}

On presentation to the department, he was immediately taken to accident and emergency resus where he was resuscitated and investigated by the on call anaesthetic and surgical teams. Observations on presentation were blood pressure $127 / 75$, heart rate 99 , respiratory rate 28 , arterial oxygen saturation $\left(\mathrm{SaO}_{2}\right) 100 \%$ on $100 \%$ oxygen. Venous blood gases showed an acidotic picture with profound hypoxia (partial pressure of oxygen $2.3 \mathrm{kPa}$ and $\mathrm{SaO}_{2} 23.9 \%$ ) and a lactate of 6.6 which improved with fluid resuscitation and oxygen. His bloods revealed acute renal failure (urea 31.2 and creatinine 303) with an elevated white cell count $\left(19.1 \times 10^{9} / 1\right.$ and neutrophils $\left.15.18 \times 10^{9} / 1\right)$.

On examination, he was peritonitic and was peripherally shut down in addition to being centrally cyanosed. There was no evidence of external trauma on the chest or abdomen.

He had a series of plain chest and abdominal radiographs taken (figures 1 and 2) which showed evidence of free gas underneath the diaphragm and demonstrated dilatation of the small bowel with a positive Rigler's sign consistent with free gas in the abdominal cavity.

CT abdomen and pelvis was requested by the accident and emergency staff but a decision was made not to perform this and to take the patient for an immediate emergency laparotomy.

\section{TREATMENT}

The patient's condition continued to decline in the anaesthetic room and it was clear that urgent intervention was required. On induction, an airway was secured via an endotracheal tube and the patient began to vomit almost immediately as an nasogastric (NG) tube was being passed. In total 4.5 litres of brown vomitus was aspirated from the stomach within 5 min and more continued to drain freely during the subsequent procedure. The patient was stabilised and had a central line inserted.

A midline incision was made and immediately it became apparent that the patient had perforated. Gas escaped from the abdominal cavity upon opening the peritoneum and the viscera was covered in large amounts of brown fluid that was similar to that which was being aspirated via NG tube. The patient had a hugely distended stomach that was decompressed eventually by insertion of a large bore orogastric tube.

Examination of the abdominal contents located a $5 \mathrm{~mm}$ transverse linear perforation in the wall of the small bowel which was leaking significant amounts of brown feculent material. There was no gastric outflow obstruction. 


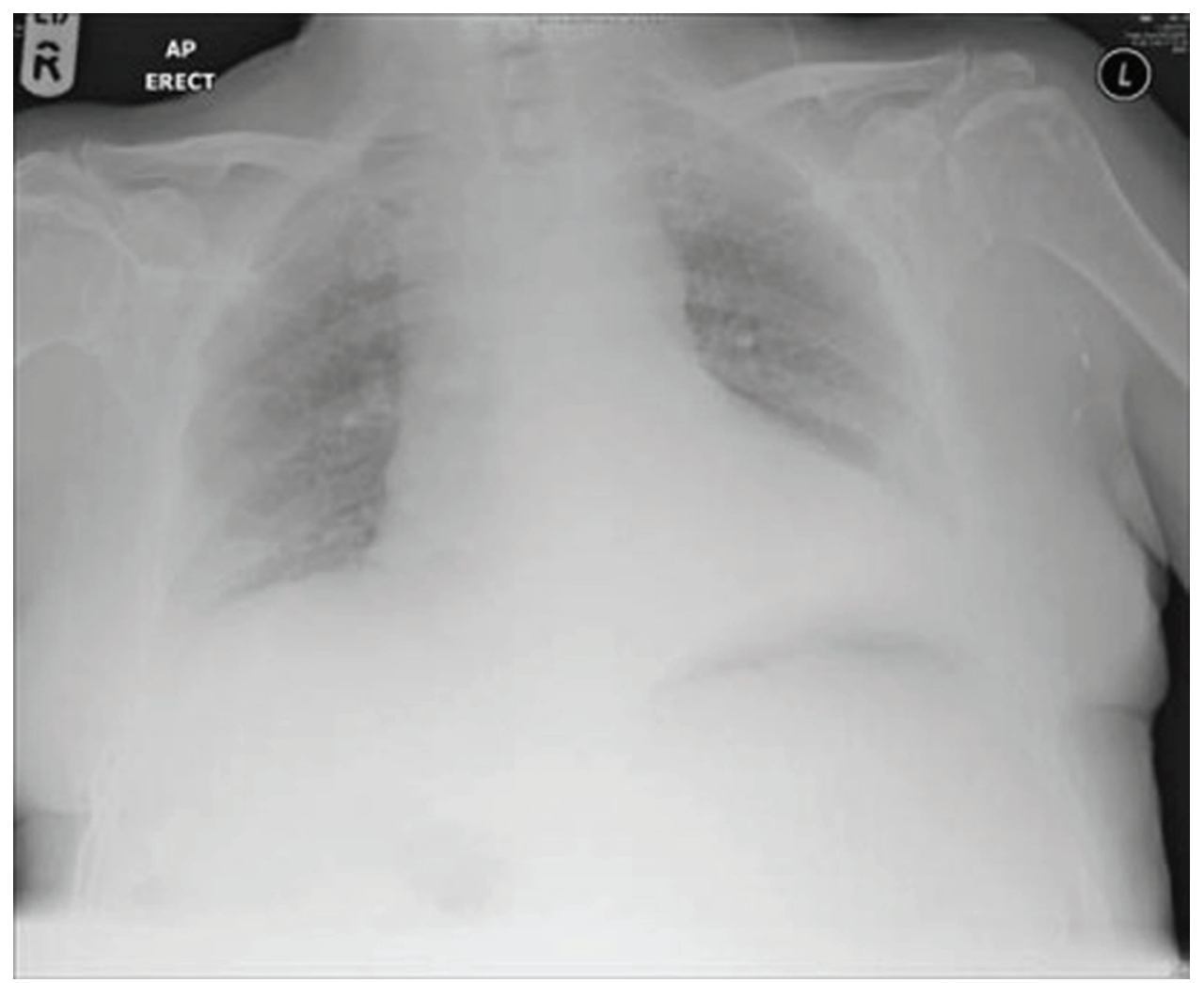

Figure 1 Chest radiograph taken on admission.

Interestingly there was no obvious evidence of localised inflammation or exudate which suggested that this was an acute perforation as opposed to a chronic ulcerative process. The defect was clamped off and repaired via a double layer of 2.0 vicryl and the bowel was lavaged with 101 of normal saline.

A full laparotomy was performed to check for further injuries. The fundus and half of the greater curvature of the stomach was clinically ischaemic. It was black/green in colour, smelt offensive and there was evidence of acute peritoneal reaction in the left upper quadrant and diaphragm along with some ecchymosis on the left hemi diaphragm. The wall of the ischaemic area of the stomach was thin, flaccid and not viable. This necrotic portion of the stomach was therefore excised (figure 3) using a GIA stapler oversewn with 2.0 PDS. No other injuries were identified.

A further washout was performed and the abdomen closed.

\section{Histology}

Macroscopic examination showed a partial gastrectomy specimen measuring $16 \mathrm{~cm}$ along the stapled margin and $23 \mathrm{~cm}$ along the greater curve. Omentum to a depth of $13 \mathrm{~cm}$ was also present. Externally the stomach appeared dusky and the stomach wall was thickened. On opening of the specimen, the mucosa had a dark brown discolouration and no obvious lesions were seen.

On microscopic examination, sections from the stomach wall showed patchy, full thickness haemorrhagic infarction in keeping with the effects of ischaemia following trauma.

\section{OUTCOME AND FOLLOW-UP}

Postoperatively the patient was admitted to intensive care and remains in a critical condition. He was intubated and ventilated and required inotropic support. He remained in acute renal failure with an element of acute tubular necrosis requiring haemofiltration and had a profoundly septic picture being actively treated with broad-spectrum antibiotics in the form of tazocin and metronidazole. Sputum cultures grew Serratia marcescans which was sensitive to tazocin. On day 3 postoperatively he was commenced on NG feeding which was cut back after large volumes were being aspirated via his NG tube. Total parenteral nutrition was implemented to ensure adequate nutrition.

On day 7 post operatively a CT scan of the patients abdomen and pelvis was requested as he remained septic despite intensive antibiotic therapy with the intensive care team querying whether or not there was the presence of an anastomotic leak. This scan identified an $8.8 \times 3.4 \mathrm{~cm}$ collection in the lesser sac which the radiologist could not determine for definite was in communication with the staple line from the recent resection. Interestingly this scan also identified minimally displaced rib fractures at the level of T9-T10 and undisplaced rib fractures at the level of T11T12. Further review of the scan resolved that while the features reported initially were highly suggestive of a localised anastomotic leak, however, artefact made this difficult to differentiate and it was the opinion of the senior consultant gastrointestinal radiologist that this collection was unlikely to be due to a leak.

Unfortunately, the lower edge of the patient's wound showed evidence of breakdown at this point with purulent discharge around the lower margins. This progressed to the 


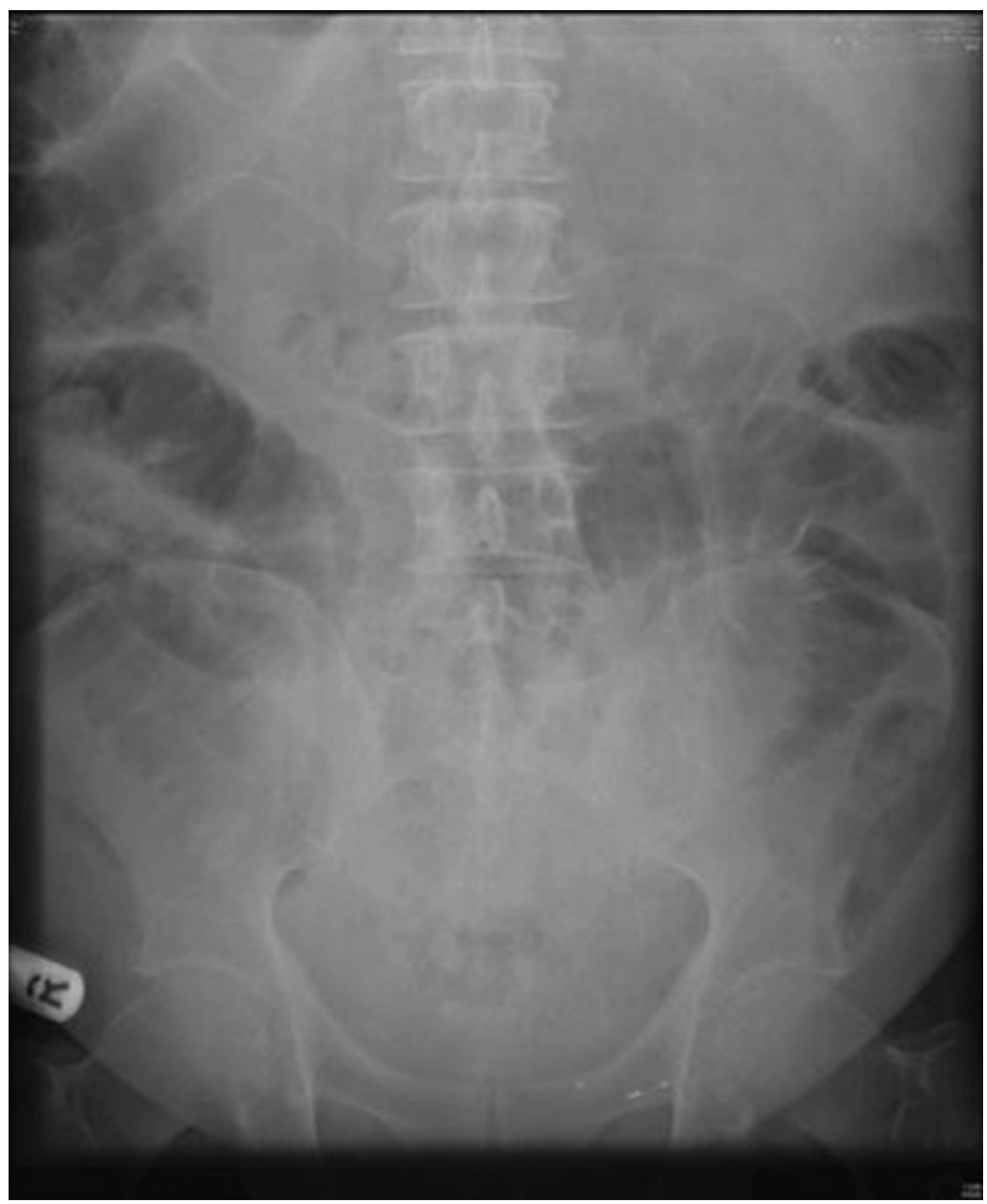

Figure 2 Abdominal radiograph taken on admission - note the positive 'Rigler's' or 'double wall' sign indicating free air in the peritoneum.

wound opening superficially a few days later. Swabs were taken which grew Candida albicans and therapy with fluconazole was commenced. A vacuum assisted closure (VAC) dressing was placed over the central abdominal wound which remains in situ with the tissue granulating well.

The patient required a chest drain for a left-sided pleural effusion, but otherwise improved steadily during the remainder of his admission to intensive treatment unit. After a total of 23 days of intensive care the patient was successfully discharged to the general ward.

The patient's rehabilitation on the general ward was encouraging. Normal feeding was eventually reinstated and good bowel function was achieved. Despite a minor hospital acquired pneumonia and transfusion of 2 units of whole blood due to persistently low haemoglobin which became symptomatic on mobilising, the patient made a remarkably good recovery.

We are pleased to say that he was discharged home 33 days after his admission with only a portable wound VAC in situ. His progress will be followed up in outpatients in 4 weeks time.

\section{DISCUSSION}

The literature reports a number of causes of acute gastric ischaemia ranging from acute dilatation secondary to excessive food intake to post operative complications. ${ }^{1}$ Many of these cases have a directly attributable mechanism of injury. Another reported case of gastric ischaemia highlights the contributory role of multiple vascular co-morbidities in the precipitation of gastric ischaemia but this again is unlikely to have been a contributory factor in our case as he had no diagnosed co-morbidities that would put him at risk of a vascular thromboembolic event. Furthermore it is generally believed that ischaemia of the stomach is very rare due to its ample blood supply. ${ }^{1}$ Many cases have been reported of ischaemia secondary to massive gastric distension but in these cases there was clear evidence of gastric outflow obstruction, small bowel obstruction or excessive intake 


\section{BMJ Case Reports}

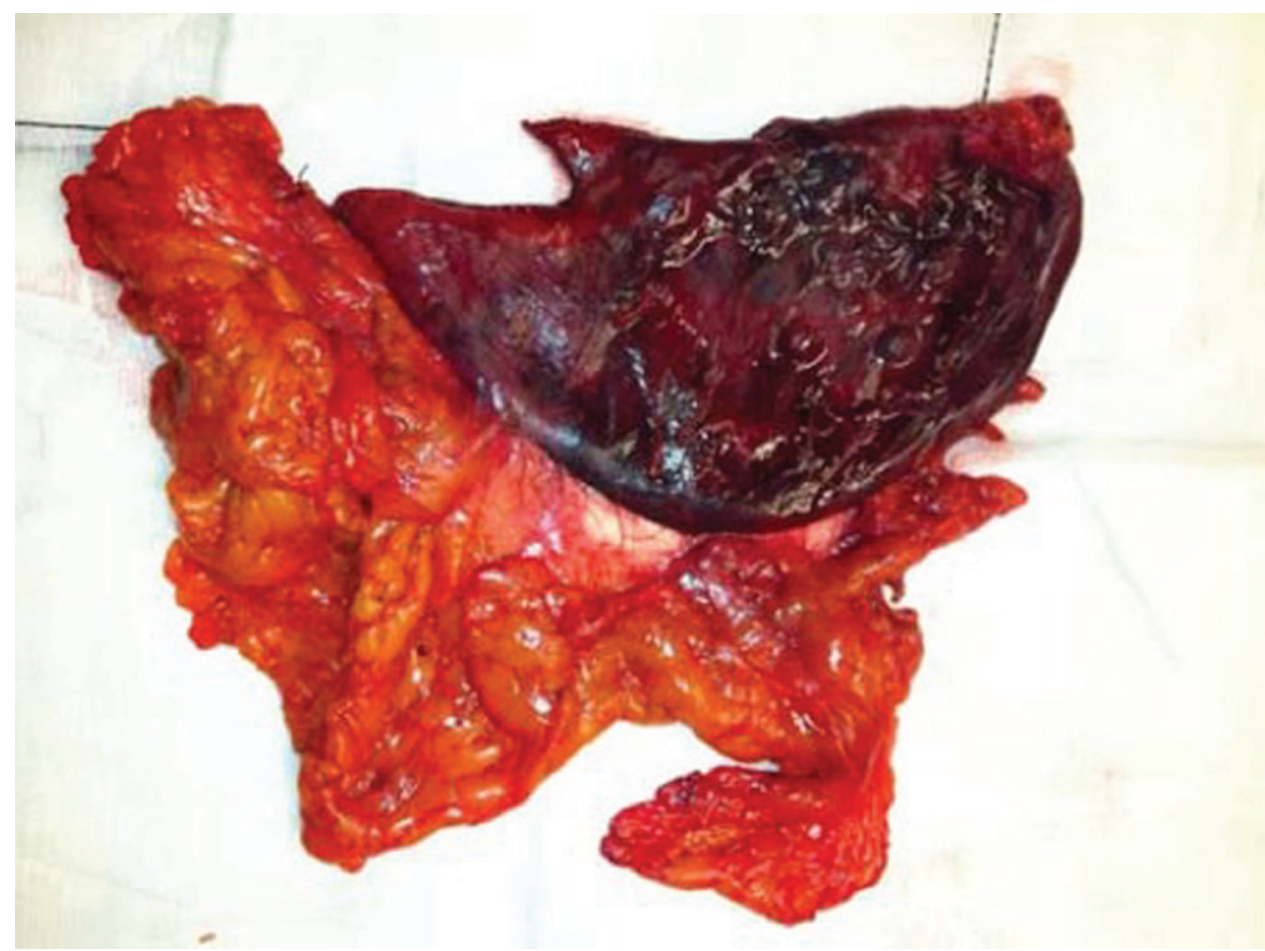

of food. ${ }^{2}{ }^{3}$ In our case the gastric outflow tract remained apparently patent, no bowel obstruction existed and the patient had not eaten for 5 days.

Unfortunately, we will never know the exact mechanism that precipitated the injuries seen in this patient. It may be that the patient perforated his bowel on a fractured rib which then caused an ileus and subsequent acute gastric dilatation leading to necrosis. However, there was no evidence of a puncture wound to the overlying tissues and radiological evidence of the rib fractures shown makes this unlikely. There remains the possibility, supported by the histological evidence that the gastric injuries were secondary to blunt trauma that resulted in acute thrombosis of the gastric vessels resulting in ischaemia although Babkin et al have shown that ligation of both the arterial and venous supply to the stomach is necessary to induce ischaemia. ${ }^{1}$

A review of the current literature shows only one case similar in mechanism of injury to our case. This case, however, resulted in an isolated gastric injury, namely shearing of the gastric mucosa following a direct blow from the side of a metal skip after falling 6 feet, whereas in our case the patient suffered injury to both the stomach and small bowel. The other main difference in our case is that the patient fell on to a flat surface and did not sustain point blunt force from an object as the patient in the other authors case did. Further differences exist in the type of injury sustained. To our knowledge there are no reported cases of gastric ischaemia secondary to low impact trauma of this kind. Cases such as the one cited report mucosal injury resulting in haematemesis without perforation that required ligation and cautery with complete resolution. ${ }^{4}$ It is clear that our patients suspected presentation of ischaemia and necrosis of the stomach secondary to low energy blunt force trauma is an unusual and rare presentation.
There is some debate about the management of ischaemic lesions within the stomach with some question about whether or not total gastrectomy is preferable to partial resection as was favoured in this case. ${ }^{3}$ The main reason for favouring total gastrectomy is to guard against delayed ischaemia of the remaining stomach. Mortality for all cases of gastric ischaemia are quoted to be around $50-80 \%$ following surgical intervention.

What is clear from this case is that rapid recognition of the patient's signs and symptoms led to effective management and fortunately a good outcome and resolution. It also highlights the importance of ensuring a full laparotomy and proper examination is carried out in patients who have suffered abdominal trauma, even if the initial injury occurred several days before.

\section{Learning points}

Always retain a high index of suspicion for patients who have suffered abdominal trauma, even if it has occurred several days before.

- Early resuscitation and decisive action to operate can make a difference in the outcome of these patients.

- Though rare, gastric ischaemia is an important diagnosis to bear in mind as it is associated with a high morbidity and mortality.

- It is important to always ensure a full and proper examination of all of the abdominal contents when undertaking an emergency laparotomy.

Competing interests None.

Patient consent Obtained. 


\section{REFERENCES}

1. Ammori JB, McHugh J, Cimmino VM. Acute gastric necrosis: assessing the risk factors. Surg Rounds 2007;30:112-17.

2. Lewis $\mathbf{S}$, Holbrook A, Hersch P. An unusual case of massive gastric distension with catastrophic sequelae. Acta Anaesthesiol Scand 2005;49:95-7.
3. Steen S, Lamont J, Petrey L. Acute gastric dilation and ischemia secondary to small bowel obstruction. Proc (Bayl Univ Med Cent) 2008;21:15-17.

4. Gestring ML, Stassen NA, Cheng JD, et al. Isolated gastric injury after blunt abdominal trauma. J Trauma 2006;61:1021.

This pdf has been created automatically from the final edited text and images.

Copyright 2011 BMJ Publishing Group. All rights reserved. For permission to reuse any of this content visit

http://group.bmj.com/group/rights-licensing/permissions.

BMJ Case Report Fellows may re-use this article for personal use and teaching without any further permission.

Please cite this article as follows (you will need to access the article online to obtain the date of publication).

Dunne MJ, Ferreira I, Thorpe B, Ajeel A, Ali H, Bailey C. Gastric ischaemia following a fall. BMJ Case Reports 2011;10.1136/bcr.04.2011.4139, date of publication

Become a Fellow of BMJ Case Reports today and you can:

- Submit as many cases as you like

- Enjoy fast sympathetic peer review and rapid publication of accepted articles

- Access all the published articles

- Re-use any of the published material for personal use and teaching without further permission

For information on Institutional Fellowships contact consortiasales@bmjgroup.com

Visit casereports.bmj.com for more articles like this and to become a Fellow 